\title{
Major lower limb amputation in diabetic patients: development during 1982 to 1993
}

\section{B . E bskov, L , E bskov}

The D anish A mputation R egister, D epartment of O rthopaedic Surgery, H erlev U niversity H ospital, H erlev, D enmark

Summary This study analyses 2848 primary major lower limb amputations in diabetic individuals during the period 1982-1993. The male:female sex ratio (mean 1.18) increased, while the mean age at the primary amputation was constant (70.96 years) during the period. The incidence uniformly decreased for both men and women by 0.96 per year. A subdivision of the total population into three age groups $(<50$, $50-70,>70$ years), shows a 0.95 decrease per year with no significant difference between the groups. The decrease in incidence during the period 1987-
1993 appeared specifically related to insulin-dependent diabetes mellitus (0.92), whereas the incidence of amputations in non-insulin-dependent diabetic patients was constant. The overall decrease of incidence during the period ( $40 \%$ ) does not fully meet the target specified in the St. Vincent Declaration. [Diabetologia (1996) 39: 1607-1610]

Keywords A mputation, macroangiopathy, peripheral vascular disease, complications.
O ver a number of years significant improvement has taken place in the treatment aimed at achieving near-normoglycaemia in diabetes mellitus. Understanding and treatment of diabetic complications has also improved, primarily regarding diabetic nephrophy and neuropathy. Implementation of diabetic self-care programmes, establishment of specialised, publicly subsidized foot clinics, and improvement in vascular and orthopaedic surgery took place during the $1980 \mathrm{~s}$.

The exact number of diabetic patients in D enmark is not known. It is estimated that 20000 persons have insulin-dependent diabetes (IDDM), and approximately 70000 have non-insulin-dependent diabetes treated by oral medication or diet, approximately 20000 have insulin-treated NIDDM and probably

Corresponding author: Dr. B. E bskov, Department of O rthopaedic Surgery, H erlev U niversity H ospital, D K -2730 H erlev, D enmark

A bbreviations: IDDM, Insulin-dependent diabetes mellitus; NIDDM, non-insulin-dependent diabetes mellitus; DAR, $D$ anish $A$ mputation R egister; NPR, N ational Patient R egister; ICD, International Classification of $D$ iseases. about 40000 have undiagnosed diabetes. Thus, diabetic patients represent almost 3\% of the total population averaging 5.1 million. It is evident that, besides the impact on quality of life, diabetes is also a substantial economic problem.

In the St. Vincent D eclaration A ction Programme 1992 [1] a number of five-year targets were outlined. $O$ ne being the intention to reduce by one half the rate of limb amputation due to diabetic gangrene. The objective of this paper is to evaluate the present status in D enmark.

Some demographic variations are of epidemiological relevance. D uring the period under study the proportion of older age groups in the population has steadily increased (e.g. $25 \%$ increase of individuals older that 75 years). This would theoretically influence the number of patients with NIDDM more than the number of patients with IDDM.

The total number of diabetic individuals has been estimated to have increased by $1 \%$ per year over a number of years. While the total number of smokers has decreased, that of female smokers has increased and the number of heavy smokers (i.e. more than 25 cigarettes per day) has stabilized. The number of 
individuals severely overweight has considerably increased during the past few years.

\section{Subjects and methods}

Between 1972-1979 the Danish A mputation R egister (DA R ) based its statistics and analyses upon detailed reports, voluntarily submitted by a number of orthopaedic and surgical departments, situated throughout the country, but never achieving more than $50-70 \%$ in total. Since 1978 the DA R has based its statistics on data from the National Patient R egister (NPR). The reliability of this database has been found to be adequate for epidemiology studies [2-6]. The N PR contains information on all admissions to non-psychiatric hospital departments. Since reporting to the NPR is required by law, national coverage is ensured.

The present study is based upon the DA R records from 1982 to 1993 . The total number of primary amputations was 2848.

\section{D efinitions}

P rimary amputation: the first admission of a patient for amputation of the lower limb (excluding toe(s)).

Following amputations: any admission excluding the first for amputation of the ipsi- or contralateral limb (excluding toe(s)). Major amputation: amputations at the transtibial level, through knee, and transfemoral or through hip.

\section{L imitations of data in the NPR}

The NPR data concerning operation (amputation) on paired organs, including extremities, does not specify right or left side. Consequently, it is not possible to deduce whether "following" amputations are ipsi- or contralateral. A mputation of toes are excluded from this study because the N PR only includes information concerning patients admitted to a hospital, not to outpatient clinics, where many toe amputations are carried out.

$\mathrm{D}$ ata concerning age at diabetes diagnosis, and data on the frequency and quality of ambulatory control is not accessible. Prior to 1987 all case of diabetes were reported to the N PR under one International Classification of Disease (ICD) VIII code, thus rendering distinction between IDDM and NIDDM impossible. Since 1987 the system has allowed reporting of IDDM and NIDDM under separate code numbers. H owever, no reliability studies have been carried out, thus necessitating caution in the interpretation of these data.

The present study is based upon analysis of primary amputations. However, it is estimated that about $20 \%$ of these have already had one or more toe amputations prior to the inclusion in our series.

\section{Statistical analysis}

Poisson regression analysis was used with a level of significance of $5 \%$.

\section{Results}

The mean age during the study period was almost constant at 70.96 years (range $25-97$ ). The male to

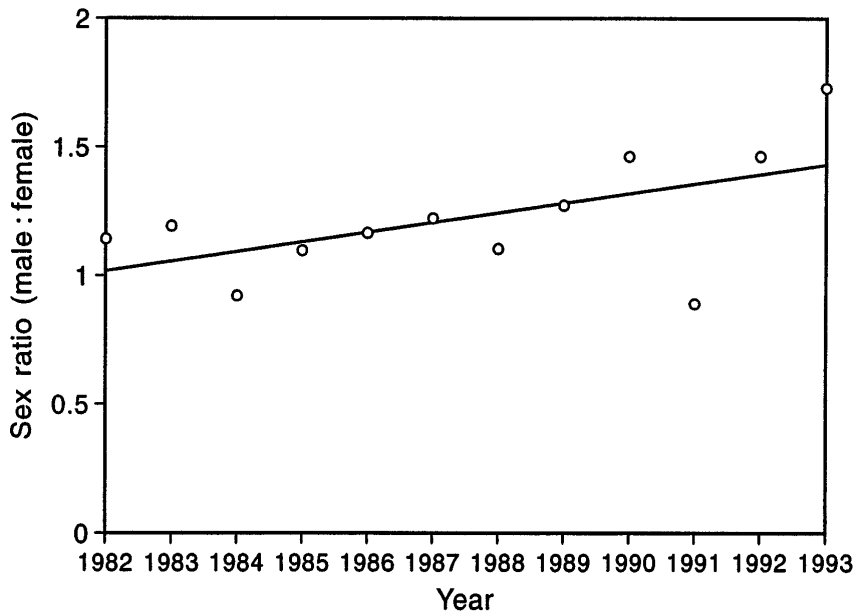

Fig. 1. $M$ ale to female sex ratio for each year during the period 1982 to 1993. The linear regression line is shown

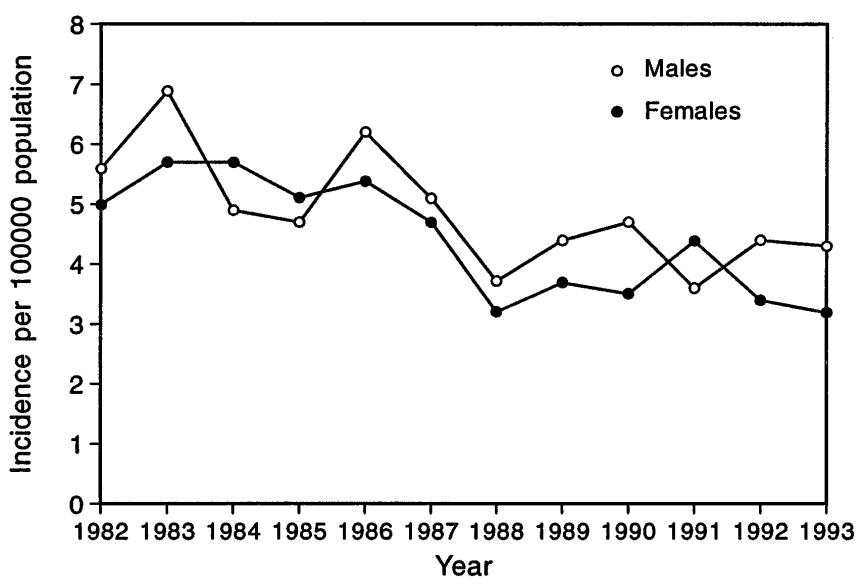

Fig. 2. Incidence per 100000 population for males and females. Poisson regression $=0.96$ (95\% confidence limits $0.95-0.97$ ), $(p=0.19)$

female ratio was increasing (Fig. 1). The median sex ratio was 1.18 (range $0.89-1.73$, SD 0.227 ).

Figure 2 shows the incidence of amputation per 100000 population for men and women. The reduction of incidence was constant during the period at $0.96 \mathrm{per}$ year ( $95 \%$ confidence limits $0.95-0.97)$. N o significant difference between men and women could be detected $(p=0.19)$. The mean incidence per 100000 population for men was 4.7 (range 3.6-6.9, SD 0.926) and for women 4.55 (range 3.2-5.7, SD 0.935). Figures 3, 4 and 5 show the age-specific incidence for the age-group younger than 50 years, between 50 and 70 years and older than 70 years. Poisson regression analysis shows that the change during the period under study was the same for all three age groups analysed $(p=0.07)$ with a 0.95 reduction per year ( $95 \%$ confidence limits 0.94-0.96). Separation of the diabetic group into IDDM and NIDDM is possible after 1987. U nder the assumptions that: 1) the number of patients with NIDDM and IDDM was constant during the period 


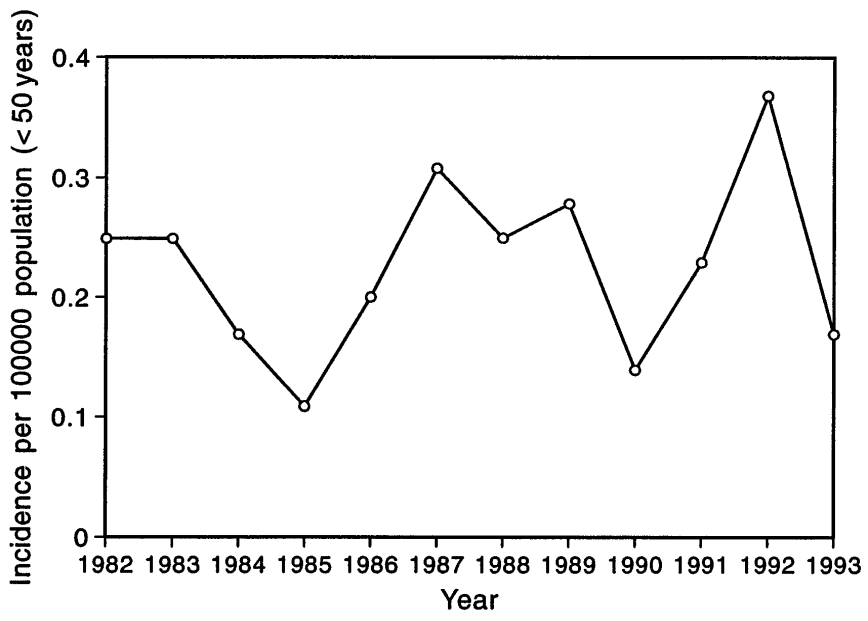

Fig. 3. Incidence per 100000 population for diabetic patients younger than 50 years. Poisson regression $=0.95$ ( $95 \%$ confidence limits 0.94-0.96)

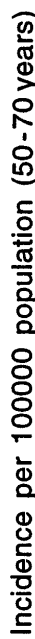

Fig. 4. Incidence per 100000 population for diabetic patients between 50 and 70 years. Poisson regression $=0.95$ (95\% confidence limits 0.94-0.96)

1987-1993 and 2) the number of patients with NIDD M averaged 90000 and ID D M 20000, it is possible to tentatively estimate the amputation incidence for individuals at risk (Fig. 6). Poisson regression analysis shows that the incidence of NIDDM amputation was constant over the period, whereas the incidence of ID D M decreased by 0.92 per year ( $95 \%$ confidence limits 0.84-0.99). The median incidence in the NIDDM group was 111.1 (range 103.3-190, $S D=27.93$ ) and in the ID D M group the median incidence was 360 ( range 190-375, SD =67.33).

\section{Discussion}

The trends regarding the incidence of diabetic amputations have previously been analysed by the DA R

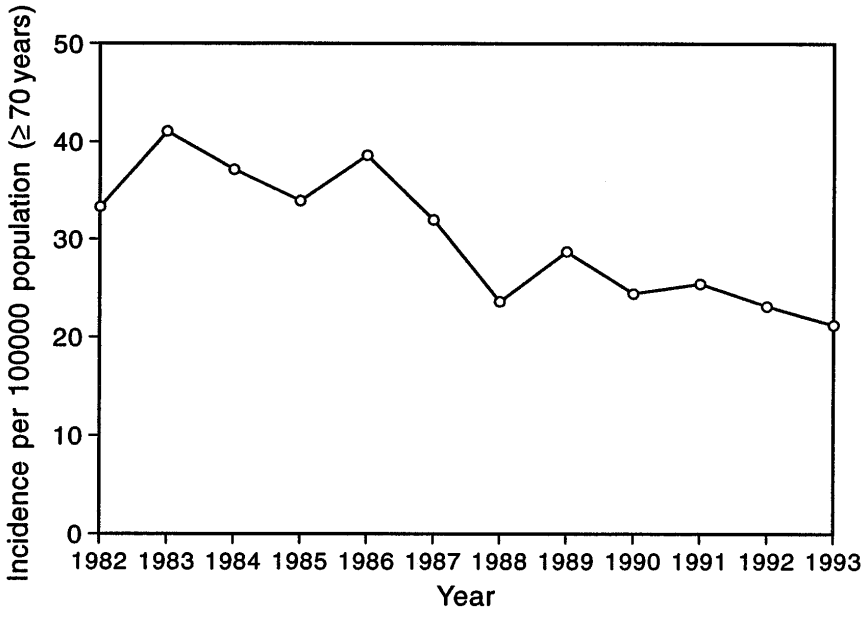

Fig. 5. Incidence per 100000 population for diabetic patients older than 70 years. Poisson regression $=0.95$ (95\% confidence limits 0.94-0.96)

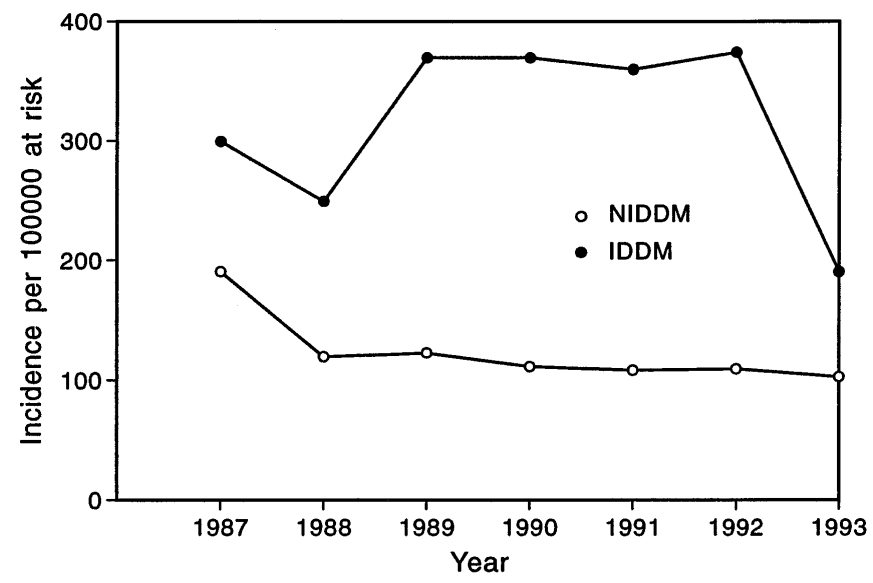

Fig. 6. Incidence per 100000 individuals at risk i.e. 90000 patients with NIDDM and 20000 with IDDM. The poisson regression for the NIDDM $=1$ (no reduction per year) and 0.92 for the ID D M group (95\% confidence limits 0.84-0.99)

[7] when significant reduction was found. O ther studies [8-13] have found similar tendencies in material covering selected geographical sub-areas. The present study analyses the reduction at the national level.

The share of men among the diabetic amputees is increasing (i.e. an increasing sex-ratio) although it is not known why, but the decrease in incidence was uniform, irrespective of sex. The phenomonen has not been described in previous studies. It should be mentioned that among other smoke-related diseases such as lung cancer the share of women is steadily increasing. There is no indication that the male:female sex-ratio among patients with diabetes has changed. In fact we had expected to find otherwise because women form the major part of the increase noticed in the elderly part of the population. R egarding the three analysed age groups, one would suspect the decrease to be 
greatest in the age group older than 70 years. However, statistical analysis shows that this is only a visual impression. The overall reduction in the incidence of lower limb amputation among diabetic individuals is uniformly distributed over the age groups. It is important to note that the mean age at primary amputation did not change during the period. B ecause the detected decrease in amputation incidence was not specifically related to either gender or age, we found it useful to analyse NIDD M as compared to IDDM. A s noted in the description of the NPR data, the recordings could have incorrect coding of the patients with insulin-treated NIDDM, and the results presented should be interpreted with caution. A decrease seen in the IDDM group and not in the NIDDM group was surprising, considering the similarity between NID D M patients and those with amputations due to non-diabetic vascular insufficiency, where a more convincing decrease has been observed [14]. I t should also be mentioned that the low incidence of ID D M amputation in 1993 influenced the outcome of the Poisson regression. However, only future development can show whether the amputation incidence in the ID D M group will continue to decrease or whether ID D M amputations will reach the steady-state which seems to be a reality in the NID DM group.

$R$ egarding the five-year targets of reduction in the number of lower limb amputations by one half, the study concluded this has not yet been achieved in D enmark. H owever, with a $5 \%$ reduction per year a total reduction of 40\% over the period 1982 to 1993 is indeed a promising result.

\section{References}

1. K rans H M J, Porta M , K een H (1992) D iabetes care and research in $\mathrm{E}$ urope: The St. V incent D eclaration A ction Programme. International D iabetes Federation E urope
2. A ndersen TF, M adsen M , L oft A (1987) Validity of surgical information from the Danish National Patient Register with particular attention to the analysis of regional variations in the hysterectomy rates. U geskr Læger 149/36: 2420-2422

3. M adsen M, Balling $H$, E riksen L S (1990) The validity of the diagnosis of acute myocardial infarction in two $D$ anish registers: The Heart R egister compared with the $\mathrm{N}$ ational Patient R egister. U geskr L æger 152: 308-314

4. National Health Board (1984) Evaluation of the National Patient Register, A pilot study. Hospital statistic II:19: 1984. N ational H ealth B oard, Copenhagen

5. Schmidt L, D amsgaard M T, N ielsen J M (1989) The validity of some abortion diagnoses in the Danish Hospital Discharge R egister. U geskr L æger 151: 3478-3482

6. Seidelin CM , E ickhoff JH (1995) A mputation and arterial reconstruction in peripheral occlusive arterial disease in D enmark 1977-1993. U geskr L æger 157: 5985-5989

7. E bskov LB (1992) E pidemiology of lower limb amputations in diabetics in Denmark (1980 to 1989). Int Orthopaedics (SICOT) 15: 285-288

8. Edmonds ME, Bludell MP, Morris ME et al. (1986) Improved survival of the diabetic foot: the role of a specialised foot clinic. Q J M ed 60: 763-771

9. Falkenberg M (1990) M etabolic control and amputations among diabetics in primary health care - a population based intensified program governed by patient education. Scand J Prim H ealth Care 8: 25-29

10. R unyan JW (1975) The M emphis chronic disease program. JA M A 231: 264-267

11. D avidson J K, A logna M, Goldsmith M, Borden J (1981) A ssessment of Program E ffectiveness at Grady M emorial H ospital. In: Steiner G., L awrence P. A . (eds) E ducation of diabetic patients. Springer, Berlin Heidelberg N ew York, pp 329-348

12. L ippman HI (1979) M ust loss of limb be a consequence of diabetes mellitus? D iabetes Care 2: 432-436

13. Larsson J (1994) Lower extremity amputation in diabetic patients. Thesis, L und

14. E bskov L B , Schroeder TV, H olstein PE (1994) E pidemiology of leg amputations. The influence of vascular surgery. B r J Surg 81: 1600-1603 